This document was prepared in conjunction with work accomplished under Contract No. DE-AC09-96SR18500 with the U. S. Department of Energy.

\title{
DISCLAIMER
}

This report was prepared as an account of work sponsored by an agency of the United States Government. Neither the United States Government nor any agency thereof, nor any of their employees, nor any of their contractors, subcontractors or their employees, makes any warranty, express or implied, or assumes any legal liability or responsibility for the accuracy, completeness, or any third party's use or the results of such use of any information, apparatus, product, or process disclosed, or represents that its use would not infringe privately owned rights. Reference herein to any specific commercial product, process, or service by trade name, trademark, manufacturer, or otherwise, does not necessarily constitute or imply its endorsement, recommendation, or favoring by the United States Government or any agency thereof or its contractors or subcontractors. The views and opinions of authors expressed herein do not necessarily state or reflect those of the United States Government or any agency thereof. 


\section{Drop Simulation of 6M Drum with Locking-Ring Closure and Liquid Contents}

by

TSU-TE WU

Westinghouse Savannah River Company

Savannah River Site

Aiken, South Carolina 29808

Additional Authors:

This paper was prepared in connection with work done under the above contract number with the U. S.

Department of Energy. By acceptance of this paper, the publisher and/or recipient acknowledges the U. S. Government's right to retain a nonexclusive, royalty-free license in and to any copyright covering this paper, along with the right to reproduce and to authorize others to reproduce all or part of the copyrighted paper. 
PVP2006-ICPVT11-93323

\title{
DROP SIMULATION OF 6M DRUM WITH LOCKING-RING CLOSURE AND LIQUID CONTENTS
}

\author{
Tsu-te Wu \\ Savannah River National Laboratory \\ Aiken, South Carolina 29803 \\ (803) 725-8201, tsu-te.wu@srnl.doe.gov
}

\begin{abstract}
This paper presents the dynamic simulation of the $6 \mathrm{M}$ drum with a locking-ring type closure subjected to a 4.9-foot drop. The drum is filled with water to 98 percent of overflow capacity. A three dimensional finite-element model consisting of metallic, liquid and rubber gasket components is used in the simulation. The water is represented by a hydrodynamic material model in which the material's volume strength is determined by an equation of state. The explicit numerical method based on the theory of wave propagation is used to determine the combined structural response to the torque load for tightening the locking-ring closure and to the impact load due to the drop.
\end{abstract}

\section{INTRODUCTION}

Open-head drums are widely used to transport hazardous materials. The top closure of a drum-type package typically consists of a formed drum closure with a dished center and a raised rim of inverted "J" cross section. The channel of the "J" section contains a gasket and engages the curl or rolled rim of the drum when it is installed. The closure is retained by a " $\mathrm{C}$ " section clamp ring which is pulled tight, circumferentially, by a bolt, which passes through the lugs located on either side of the gap in the ring.

The open-head drums used for transporting hazardous materials are required to pass the 4.9-foot drop test in compliance with the code of federal regulations, Title 49 of the CFR 178.603 (Reference 1). The explicit method of the finite-element analysis has been commonly used to simulate the drop test of radioactive material shipping packages. The possibility of the locking-ring closure separating from the drum used as the overpack of the radioactive material package due to an impact load was previously investigated by Wu, Gelder and Smith (Reference 2). The numerical technique used in Reference 2 for evaluating the residue stresses is modified for this work. In addition, the contents of the drum are liquid instead of solid.

\section{MATERIAL PROPERTIES}

The material of the drum is carbon steel and its properties are given in Reference 3. The material of the gasket between the closure lid and the drum rim is rubber, and the properties used in this analysis are the same as discussed in Reference 2.

The water is represented by the hydrodynamic material model in which the material's volumetric strength is determined by an equation of state; namely,

$$
p=K \varepsilon_{v o l}
$$

where $K$ is the bulk modulus and $\varepsilon_{v o l}$ is the volumetric strain.

The hydrodynamic material model expressed in the linear $U_{s}-U_{p}$ form is provided in Reference 4 as follows.

$$
p=\frac{\rho_{o} c_{o}^{2} \eta}{(1-s \eta)^{2}}\left(1-\frac{\Gamma_{o} \eta}{2}\right)+\Gamma_{o} \rho_{o} E_{m}
$$

$$
\text { where } \begin{aligned}
\rho_{o} & =\text { reference density } \\
c_{o} & =\text { sonic speed } \\
\Gamma_{o} & =\text { material constant } \\
E_{m} & =\text { internal energy per unit mass } \\
s & =\text { material constant }
\end{aligned}
$$


and $\eta$ is the nominal volumetric strain and the same as $\varepsilon_{\text {vol }}$. Thus,

$$
\eta=1-\frac{\rho_{o}}{\rho}=\varepsilon_{v o l}
$$

The sonic speed in water medium is equal to the square root of the ratio of the bulk modulus to the density; namely,

$$
c_{o}=\sqrt{\frac{K}{\rho_{o}}}
$$

By setting the material constants $s$ and $\Gamma_{o}$ both equal to zero and also substituting Equations (3) and (4) into Equation (2), we can reduce Equation (2) to the form same as Equation (1). Therefore, the material model expressed as Equation (2) in the ABAQUS computer code can be used as the equation of state for the water medium.

Let the density and bulk modulus of water equal $0.000092 \mathrm{lb}-\mathrm{sec}^{2} / \mathrm{in}^{4}$ and $300000.0 \mathrm{lb} / \mathrm{in}^{2}$, respectively. Then the sonic velocity in the water medium obtained from Equation (4) is $57100 \mathrm{in} / \mathrm{sec}$. Consequently, the input values to the water material model for the equation of state are as follows.

$$
c_{o}=57100.0 \mathrm{in} / \mathrm{sec} ; \quad s=\Gamma_{o}=0
$$

\section{ANALYSIS}

The analysis is performed using the finite-element method and the ABAQUS/Explicit computer code, version 6.5 (Reference 4).

The finite-element model is developed using the MSC/PATRAN computer program (Reference 5).

\section{Finite-Element Model}

Figure 1 shows the configurations and dimensions of a 55 -gallon $6 \mathrm{M}$ drum. Figure 2 is the blow-up view of a portion of the locking ring which includes the " $\mathrm{C}$ " section of the ring, the lugs and the bolt when the locking-ring is tightened to the drum rim.

The finite-element models of the drum body, the closure lid and the bolt ring are comprised of 3D shell elements (Type S4R). The clamp bolts and the nuts, the gasket and the contents are modeled using $3 \mathrm{D}$ solid elements (C3D8R).

The drop angle between the drum axis and the target floor is 60 degrees. The orientation of the location where the initial impacts occur at the closure rim with respect to the closure lid radius passing through the middle of the clamp-ring gap is 45 degrees. Figure 3 depicts the drop angle and the orientation of the initial impact. The target floor is modeled with $3 \mathrm{D}$ rigid elements (R3D4).

Figures 4 through 7 show the details of the finiteelement models of the $6 \mathrm{M}$ drum components.

The analysis evaluates the effectiveness of the locking-ring to prevent the separation of the drum closure from the drum body after a 4.9-foot drop onto a rigid floor. To this end, the structural responses to the preload caused by the locking-ring tightening and the impact load caused by the 4.9-foot drop must both be determined. The entire analysis consists of three different load steps discussed as follows.

First Load Step: Preload Analysis for LockingRing Tightening

The torque load to tighten the closure produces the residue stresses (pre-stresses) to hold the tightened locking-ring in place after the torque load is removed. Therefore, these stresses are in self equilibrium state.

The process of bolt tightening is implemented by using the connector elements defined with respect to the local coordinates as shown in Figure 8. The Connector Element $\mathrm{A}$ is used to specify the motion of the right-hand lug relative to the left-hand lug caused by the applied torque load. Alternatively, it can also be used to specify the load applied at the right-hand lug by the applied torque. In the present analysis, the former method is used. On the other hand, the Connector Element B is used to hold the left-hand lug in the fixed location of the bolt.

The bolt tightening is simulated by specifying a smooth function of the Connector A's motion varying from zero to 1.855 inches in the time period of 0.001 seconds as shown in Figure 9. Since the original gap of the locking-ring is 1.98 inches, the gap after the bolt tightening becomes:

Gap between the two ends of the locking ring
$=1.98-1.855=0.125$ inches,

which is the maximum allowable value of the gap between the tow locking-ring ends after bolt tightening.

During the process of closure tightening, the lockingring may be tapped to reduce the friction resistance. To account for the tapping effect, the friction coefficient between the gasket and metal components is assumed to be zero during the first load step.

Second Load Step: Establishment of Impact Initial Velocity

The package will drop for 4.9 feet after the closure is tightened up. Conventionally, the velocity of the package at the end of the free fall from the height of 4.9 feet will be used as the initial velocity of the drop analysis. However, in the present case, the drum closure must be tightened by applying a torque load 
before the drop can be initiated. As a result, the subsequent drop analysis does not start at the time equal zero and thus the onset velocity of the drop impact can not be specified as an initial velocity. To overcome this obstacle, the following technique is used to establish the onset velocity of the impact analysis that follows:

The model of the drum package is intentionally placed at a small distance away from the model of the target floor. The shortest distance between the drum and the target floor in the direction normal to the target floor is approximately 0.3305 inches. The velocity of the drum package is then specified as a smooth function of the boundary condition. The onset velocity of the drop impact is:

$V_{o}=\sqrt{2 g h}=\sqrt{2 \times 386.4 \times 12 \times 4.9}=213.168 \mathrm{inch} / \mathrm{sec}$.

Since the directional cosines of the normal vector to the target floor are $(-0.353549,-0.353549,0.88603)$ with respect to the global coordinate system, the components of the onset velocity magnitude are calculated as follows.

$$
\begin{aligned}
& V_{x}=V_{y}=213.168 \times(-0.35359)=-75.365 \mathrm{in} / \mathrm{sec} \\
& V_{z}=213.168 \times 0.86603=184.61 \mathrm{in} / \mathrm{sec}
\end{aligned}
$$

The gravitational load is also applied in the same direction as that of the onset impact velocity.

\section{Third Load Step: Simulation of Drop Impact}

The boundary condition of velocity type specified in the second load step to establish the onset velocity of the impact analysis must be removed in this load step. Otherwise, the velocity value at the end of the second load step will be carried over through the period of this load step. The correct onset conditions of the impact analysis can be established by specifying a new boundary condition of velocity type without giving any data. As a result, the package will travel at the velocity created by the free fall before it strikes the target floor.

The same components of the gravitational load defined in the second load step are also applicable to the third load step.

The finite-element model of the rigid floor is fixed during the 4.9-foot drop and thus, all the six degrees of freedom of its reference node are constrained; namely,

$$
U X=U Y=U Z=R X=R Y=R Z=0
$$

The coefficient of friction between the contact interfaces of the gasket and the metal components is assumed to be 0.3 during this load step.

\section{DISCUSSION OF ANALYTICAL RESULTS}

\section{Preload Analysis for Locking-Ring Tightening}

Displacement of Right-Hand Lug As discussed in the Analysis Section, the process of locking-ring tightening is simulated by specifying the connector element motions to pull the locking-ring lugs toward each other to narrow the gap between the two ends of the locking ring.

Figure 9 shows the time history of the displacement of the right-hand lug. Since the displacement is a smooth function, there is no vibration generated by the torque load.

Energy History Figure 10 displays the time history of the energy components during the process of locking-ring tightening.

The kinetic energy caused by the motion of the locking-ring assembly during the process of drumclosure tightening first increases and then decreases smoothly in the time period from zero to 0.001 seconds while the torque load is being applied. Since the kinetic energy becomes zero when the torque is removed at the time of 0.001 seconds, the assumed rapid application of the torque load does not generate kinetic energy in addition to the 4.9-foot drop for the impact simulation. In other words, the first load step only generates the strain energy associated with the torque preload as it should.

Equivalent Strain Figure 11 shows the distribution of the equivalent strains caused by the torque load.

\section{Analysis of 4.9-Foot Drop}

Energy History The time-history plot of the combined energy for the torque preload and the 4.9foot drop is shown in Figure 12.

Deformed Shape during Impact Figure 13 depicts the impact phenomenon of the drum caused by the 4.9-foot drop. Figure 14 shows the deformed shape of the drum after the drop. The drum is severely distorted in the closure region; however, its closure is not separated from the rim

Equivalent Strain Figure 15 is the plot of equivalent plastic strain in the drum closure region.

\section{CONCLUSIONS}

The numerical technique presented in this paper is able to simulate the open-head drum with liquid contents to account for both the torque preload and the impact load. The analytical results of a $6 \mathrm{M}$ drum filled with water to 98 percent of overflow capacity indicates that, after a 4.9-foot corner drop, the lockingring is able to hold the closure and the rim tight 
although the drum closure is distorted and experiences severe plastic strains.

\section{REFERENCES}

1. Title 49 of the Code of Federal Regulations, 178.603, 1998.

2. Wu, T. T., Gelder, L. F. and Smith, A. C., "Dynamic Analysis of Radioactive Material Package with Clamp-Ring Closure," Proceeding of 2004 ASME Pressure Vessel and Piping Conference.

3. Gong, C., Spallation Impact Analysis for Plutonium Storage at K-Area, M-CLC-K00636, Rev. 0, Westinghouse Savannah River Company, Aiken, SC, January 1999

4. ABAQUS/Explicit User's Manual, Version 6.5, ABAQUS, Inc., 2005

5. MSC/PATRAN, Version 2003r2, MacNealSchwendler Corp., 2003. 


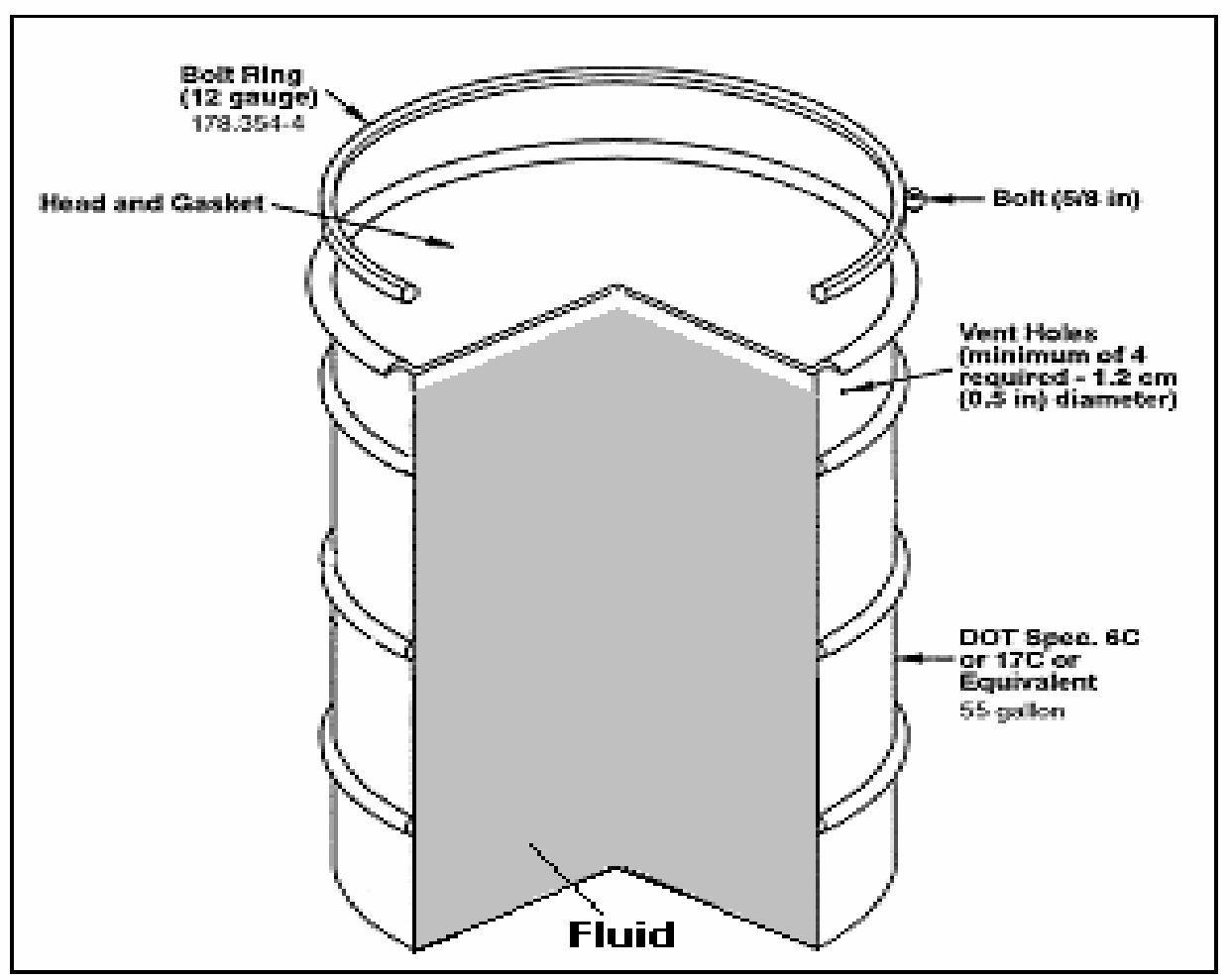

Figure 1 6M Drum with Fluid Contents

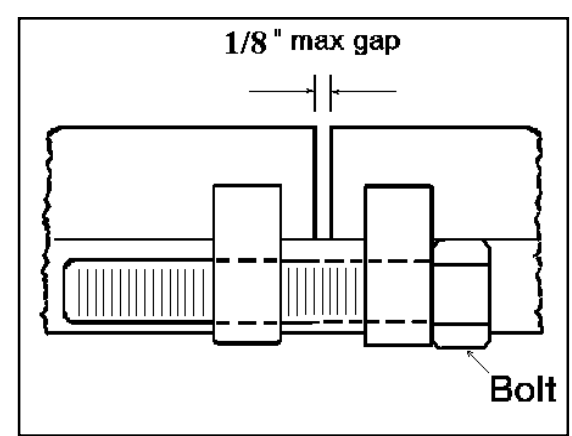

Figure 2 Configuration of Locking-Ring Closure

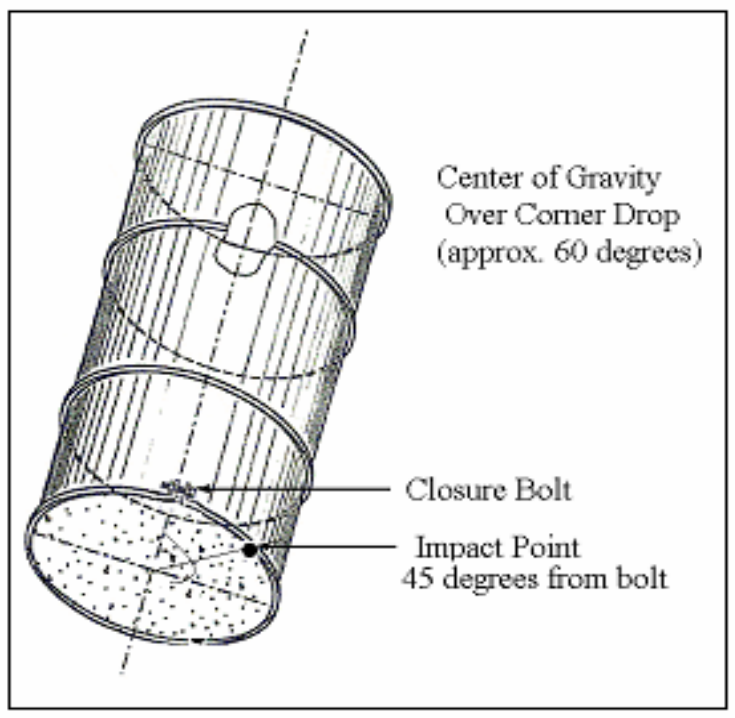

Figure 3 Illustration of Drop Angle and Impact Orientation 


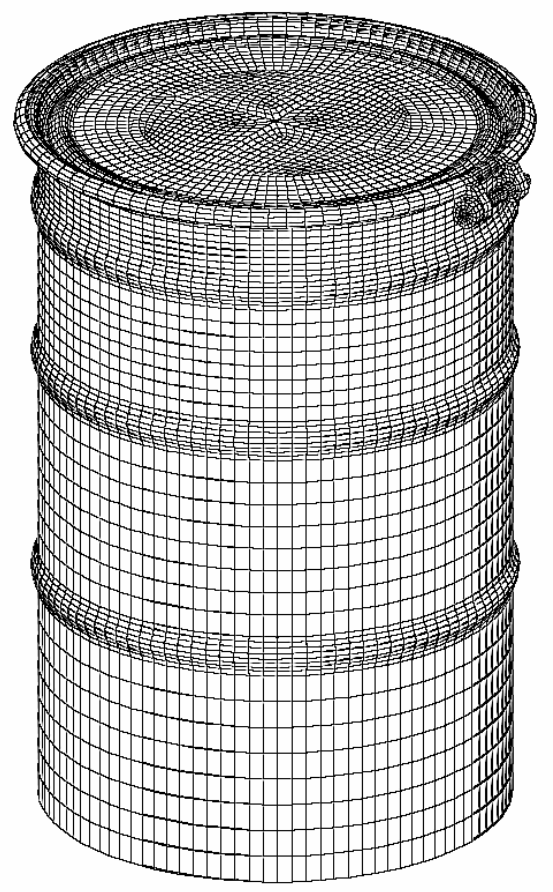

Figure 4 Finite-Element Model of 6M Drum

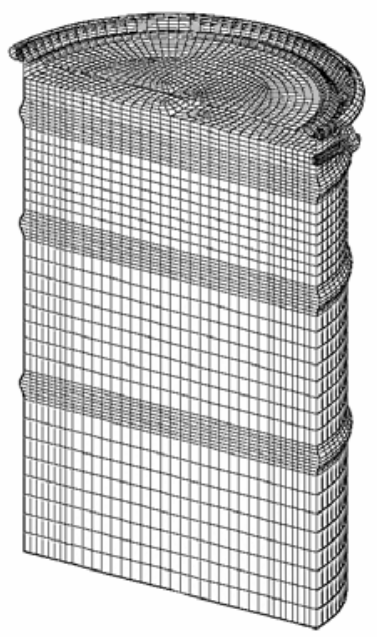

Figure 5 Cross Section of Finite-Element Model

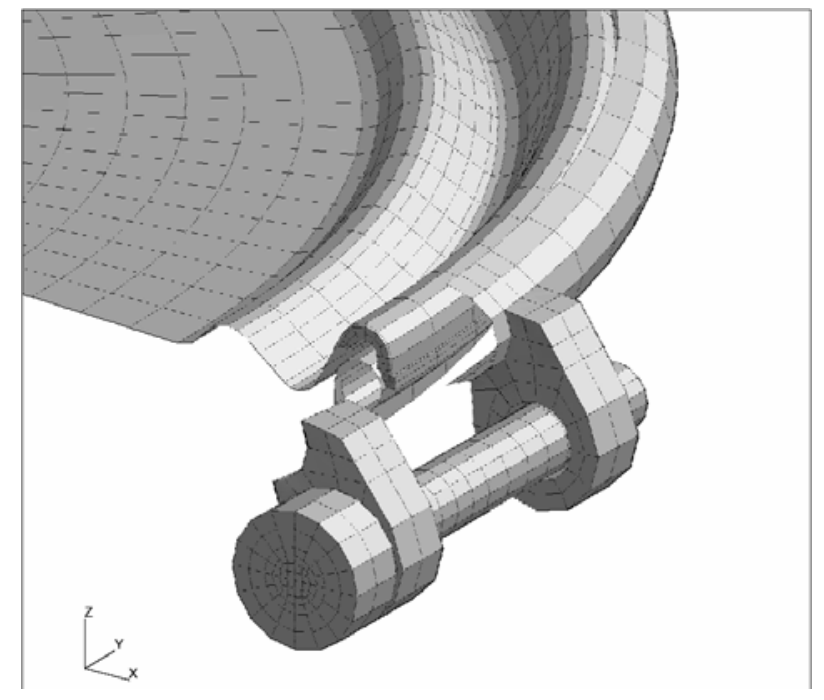

Figure 6 Blow-Up View of Locking-Ring Assembly Finite-Element Mocel

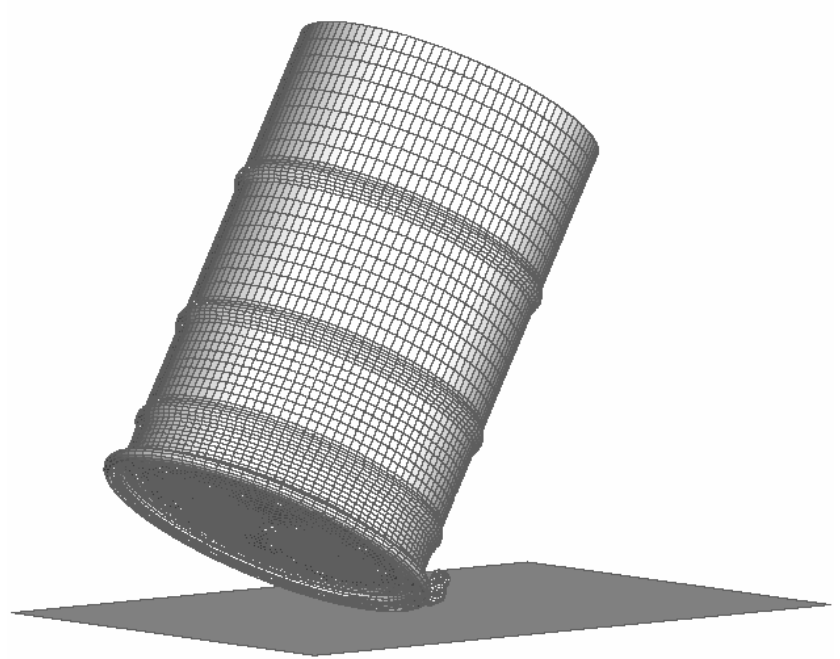

Figure 7 Full Finite-Element Model 


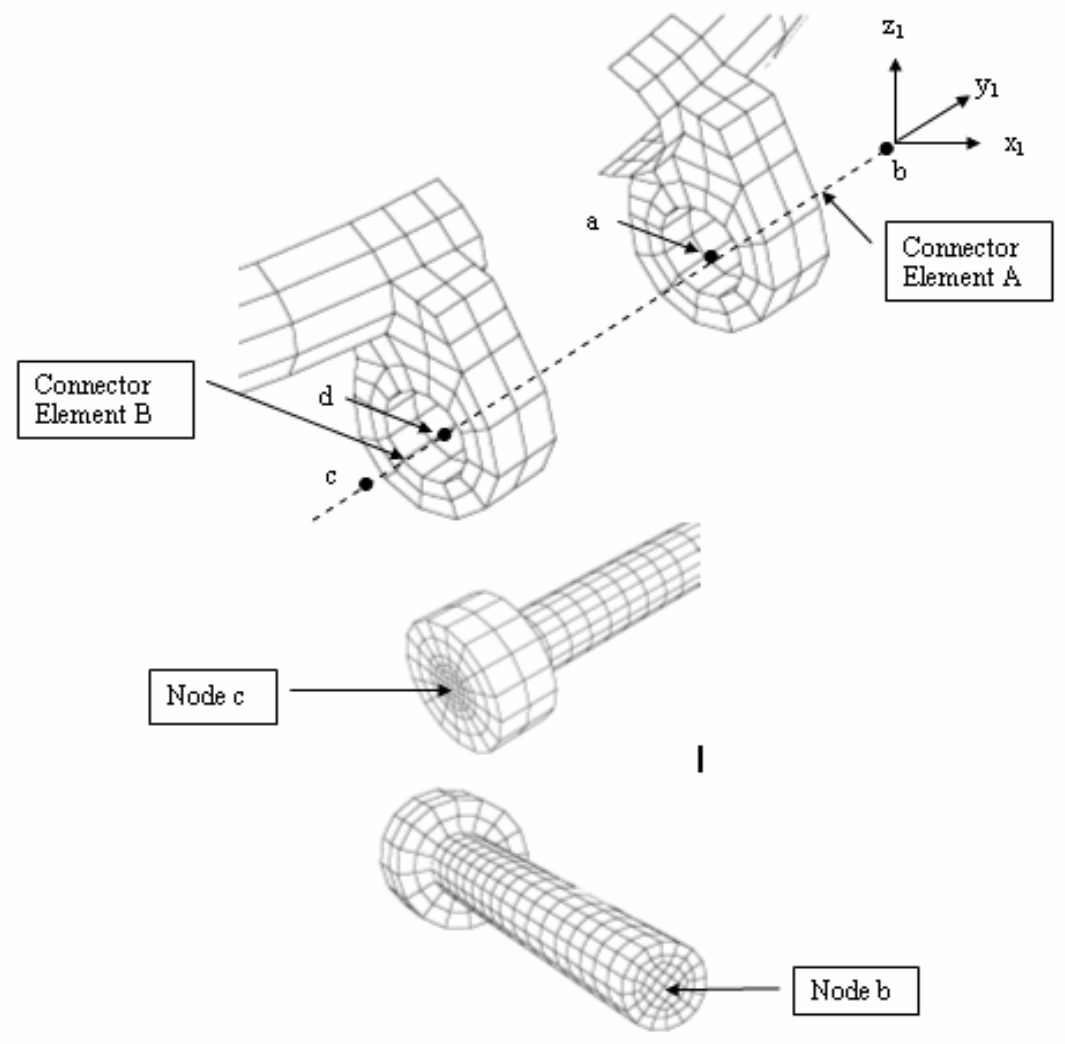

Figure 8 Connect Elements for Torque Preload Simulation

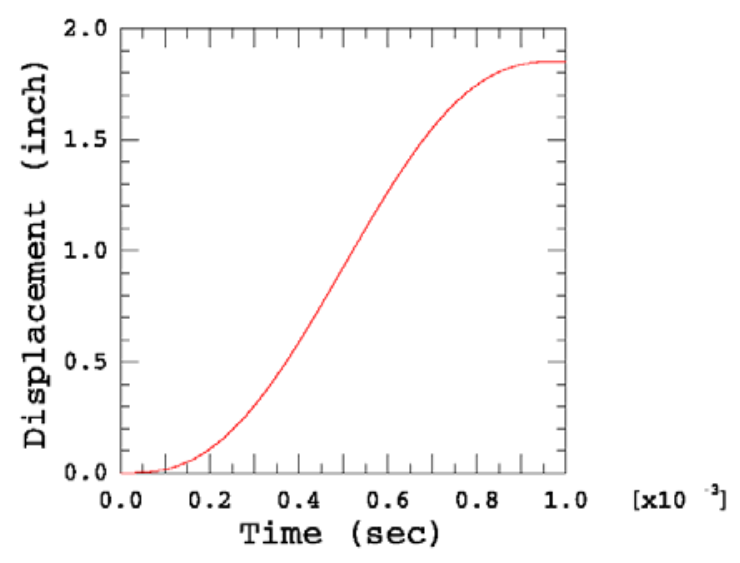

Figure 9 Time History of Closure Tightening Displacement
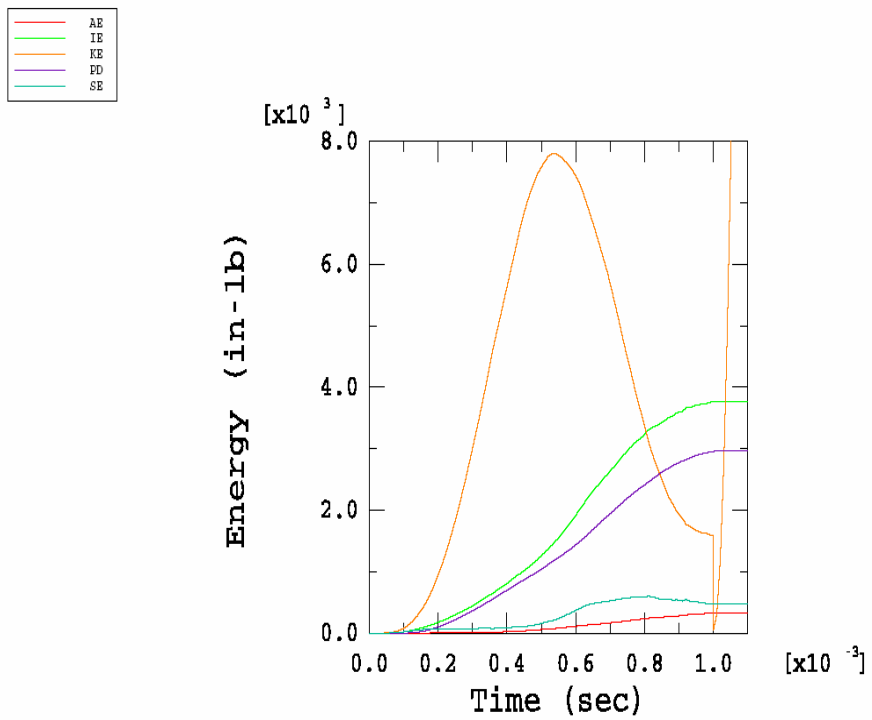

Figure 10 Time-History of Energy Components For Torque Load 


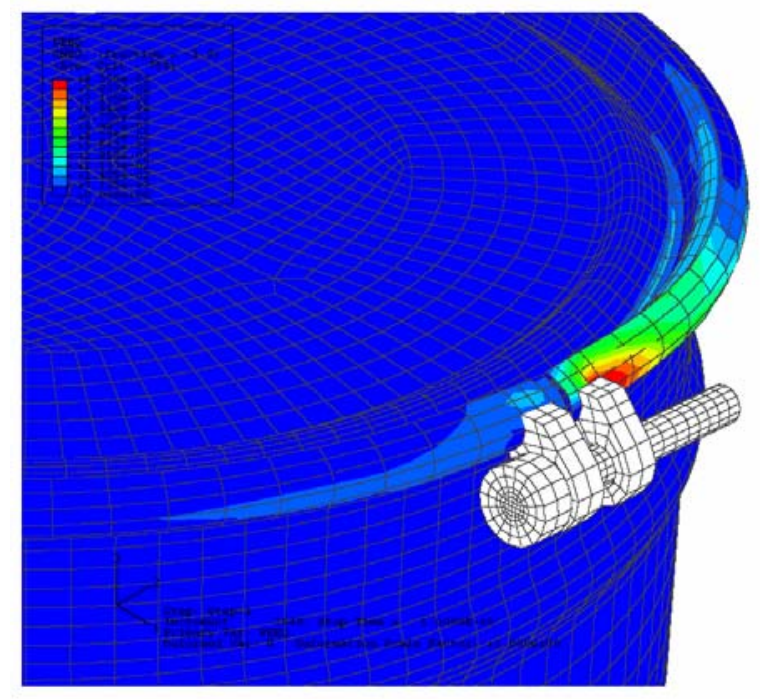

Figure 11 Equivalent Plastic Strains Caused by Locking-Ring Tightening
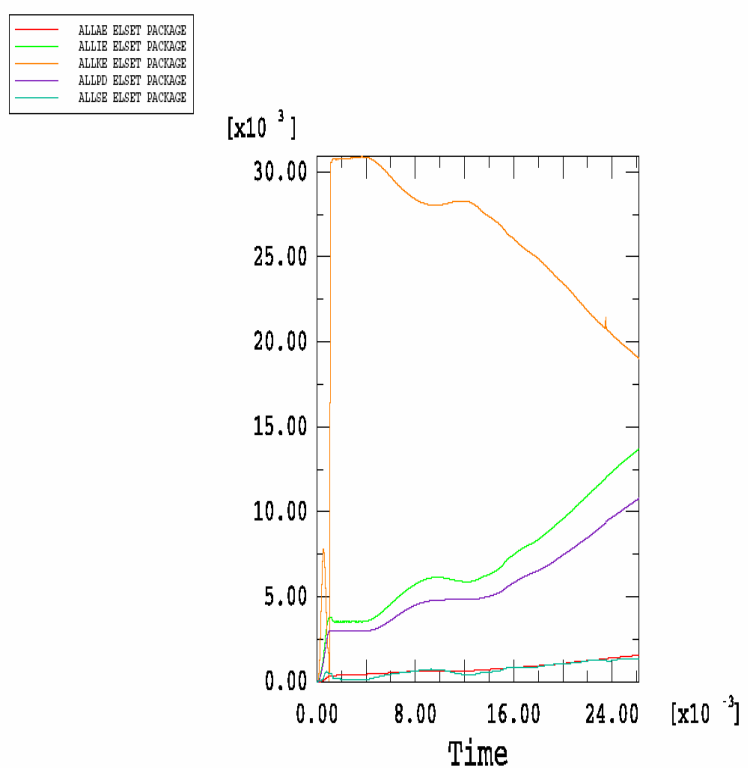

Figure 12 Time History of Energy Components for Torque Load and 4.9-Foot Drop

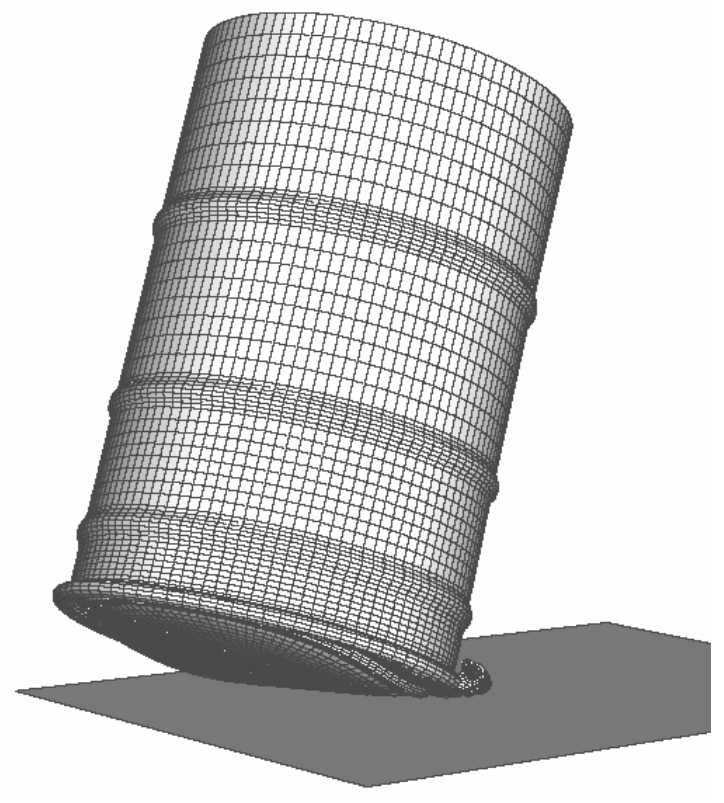

Figure 13 Deformed Shape of Drum during Impact

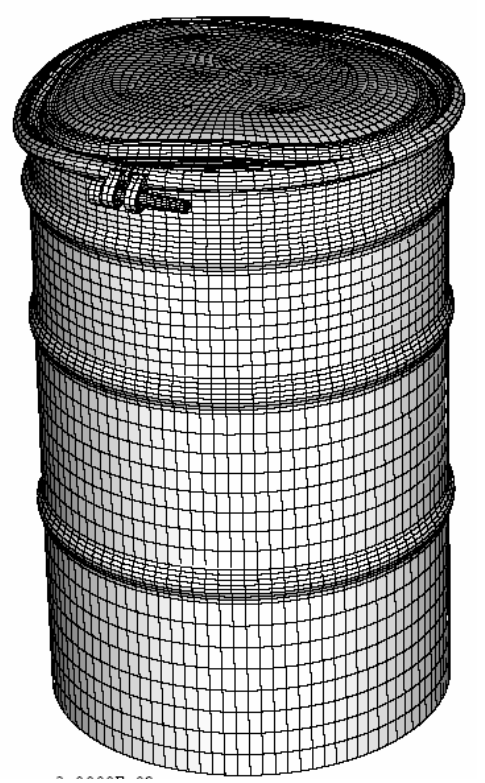

Figure 14 Deformed Shape of Drum after Drop 


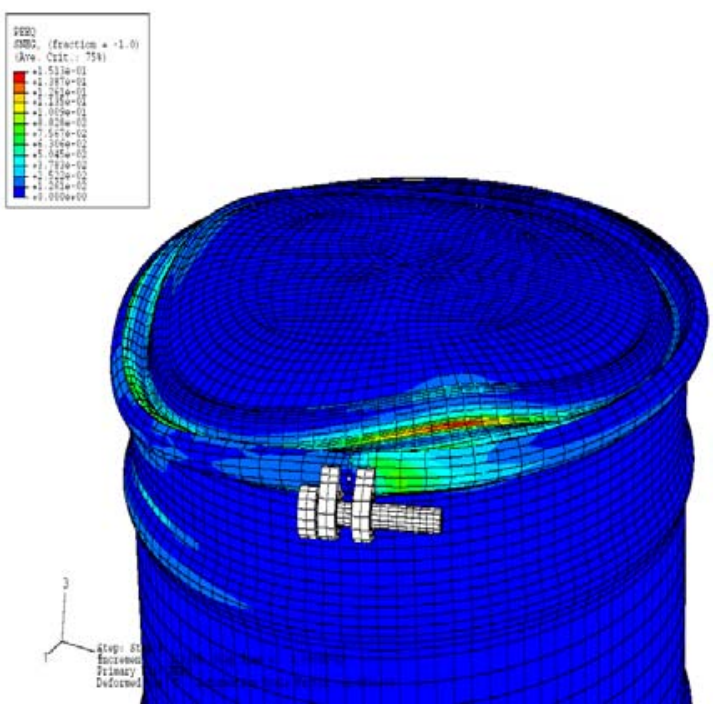

Figure 15 Equivalent Plastic Strains in Drum Lid after Drop 